\title{
Aprendizagem transformadora: a reflexão crítica na formação gerencial
}

\section{Transformative learning: a critical reflection in managerial education}

\author{
Lisiane Quadrado Closs ${ }^{1}$ \\ Claudia Simone Antonello²
}

\begin{abstract}
Resumo
Dadas as crescentes demandas por aprendizagens exigidas de gestores no atual contexto e a importância de seu papel para as organizações e a sociedade, sugere-se a necessidade de ampliar perspectivas para a educação gerencial. Esta vem recebendo críticas de correntes que destacam tanto a importância da reflexão como da reflexão crítica para a aprendizagem. Apresenta-se um levantamento de estudos brasileiros realizados sobre aprendizagem gerencial que corrobora a importância de ambas nos seus processos de aprendizagem, embora a reflexão crítica ainda seja pouco evidenciada no meio gerencial ou na educação de gestores. Propõe-se que a teoria da aprendizagem transformadora possa contribuir para a aprendizagem gerencial, suscitando reflexões críticas que favoreçam o pensamento autônomo e a liberação de pressupostos condicionados sobre o mundo, sobre os outros e sobre si, cruciais para o mundo do trabalho, para a cidadania e para a tomada de decisões morais.
\end{abstract}

Palavras-chave: aprendizagem, gestores, educação gerencial, reflexão crítica, aprendizagem transformadora.

\begin{abstract}
Due to the growing learning requests demanded of managers in the actual context and the importance of their role for organizations and society, the need for broadening management education perspectives is suggested. Business education have been criticized either by scholars that point out the reflection importance as by those that emphasize the critical reflection role for management learning. The article presents Brazilian studies developed in the management learning field which corroborate the reflection and the critical reflection importance in learning processes, although the last one is still least evident in business or in management education. It is proposed that transformative learning theory might contribute to management learning, stimulating critical reflection that favors autonomous thinking and liberates conditioned assumptions about the world, about others and themselves, crucial for work, citizenship and for moral decision making.
\end{abstract}

Keywords: learning, managers, management education, critical reflection, transformative learning.

\footnotetext{
1 Doutora em Administração pelo Programa de Pós-Graduação em Administração - PPGA/UFRGS. Professora no Instituto Brasileiro de Gestão de Negócios/IBGEN. Endereço: Instituto Brasileiro de Gestão de Negócios. Av. Protásio Alves, 2493 - Petrópolis - Porto Alegre/Rio Grande do Sul - Brasil - CEP 90410-002. E-mail: Icloss@terra.com.br

2 Doutora em Administração pela Universidade Federal do Rio Grande do Sul/UFRGS. Professora e Pesquisadora no Programa de Pós-Graduação em Administração - PPGA/UFRGS Endereço: Universidade Federal do Rio Grande do Sul - Programa de Pós-Graduação em Administração - Rua Washington Luís, n.855, sala 315 - Centro - Porto Alegre/Rio Grande do Sul - Brasil - CEP: 90010-460.

E-mail:csantonello@ea.ufrgs.br
}

Artigo submetido em outubro de 2007 e aceito em março 2009 


\section{Introdução}

Percebe-se, em andamento na sociedade atual, uma crise paradigmática que gera uma série de incertezas, angústias, medos, questionamentos. Guattari (2003) apresenta o paradoxo do momento presente: intensas transformações técnico-científicas ao lado de desequilíbrios ecológicos que ameaçam a vida no planeta e da deterioração progressiva dos modos de vida humanos. $\mathrm{O}$ autor sugere que "a noção de interesse coletivo deveria ser ampliada a empreendimentos que a curto prazo não trazem 'proveito' a ninguém, mas a longo prazo são portadores de enriquecimento processual para o futuro da humanidade" (2003, p.51).

As organizações tornam-se centrais neste contexto e, concomitantemente, causa e efeito das principais mudanças ocorridas nos últimos tempos. Elas afetam direta ou indiretamente a vida da maioria da população do globo terrestre, seja na forma de geração de emprego e de renda, na produção de bens e serviços ou na criação de subprodutos intencionais e não intencionais que trazem resultados tanto benéficos como nocivos à sociedade e ao meio ambiente (AXLEY; MCMAHON, 2006).

Desse modo, o papel dos gestores ganha importância na sociedade como um todo, não se limitando apenas às organizações. A aprendizagem gerencial recebe também maior atenção, uma vez que o tempo de aprender tornou-se permanente (GADOTTI, 2000) e o pensamento, a formulação de questionamentos, a imaginação e a criatividade são hoje essenciais (ALVES, 2005). A necessidade de desenvolvimento de um patamar de consciência mais elevado (UNGER, 1991; MORIN, 2003), especialmente por parte dos gestores, dadas as repercussões de seu trabalho para a sociedade e o meio ambiente, demanda, igualmente, processos de aprendizagem. Nessa sociedade, a educação deve servir de bússola para orientar criticamente o conhecimento, superando a visão utilitarista voltada apenas para a competitividade e a busca de resultados (GADOTTI, 2000).

As instituições de ensino, no entanto, sobretudo as voltadas à educação em Administração, tendem a reproduzir o modelo mecanicista das organizações do mundo industrializado e demonstram limitações para tratar dos desafios atuais (AXLEY; MCMAHON, 2006; NICOLINI, 2003). Educar profissionais para administrar organizações, capacitando-os para o enfrentamento das responsabilidades e desafios presentes, requer possivelmente a busca de novos modelos e processos de ensino que provoquem a transformação do pensamento e possibilitem, concomitantemente, o tratamento das dimensões econômicas, éticas, políticas, sociais e ambientais.

Uma educação com este enfoque envolveria, simultaneamente, além do desenvolvimento técnico-profissional, objetivos tais como o desenvolvimento político-social desses profissionais e o suscitar de reflexões críticas, através de processos quer formais, quer informais, já que ambos estão interligados (MORAES, 2000; ANTONELLO, 2004). Considerando-se a influência exercida por parte dos gestores sobre indivíduos, comunidades e meio ambiente, a ênfase apenas no desenvolvimento de habilidades ou no reforço de conceitos gerenciais existentes seria limitada (REYNOLDS, 1999).

Atuar em um ambiente organizacional que contempla complexidade, paradoxos, incerteza e em um contexto global permeado por constantes inovações tecnológicas, influenciado por problemáticas éticas, políticas, ambientais e econômicas, demanda, possivelmente, a ampliação de perspectivas por parte dos gestores. A compreensão dos processos de aprendizagem de gestores inseridos nesse contexto dinâmico passa, portanto, a ser um tema de vital importância no mundo contemporâneo. Dessa forma, o presente artigo tem como objetivo discutir uma abordagem alternativa para a formação gerencial, que possibilite ampliar perspectivas para os processos de aprendizagem de gestores frente ao atual contexto, mais especificamente, a teoria da aprendizagem transformadora. Para tanto, o artigo apresenta a temática da aprendizagem gerencial sob o enfoque da educação; um levantamento de estudos desenvolvidos, no Brasil, acerca da aprendizagem gerencial; a teoria da aprendizagem transformadora, suas limitações e possibilidades, como aporte teórico passível de contribuir para a educação em Administração; algumas reflexões e possibilidades de estudos futuros no Brasil.

\section{A Aprendizagem Gerencial sob o Enfoque da Educação}

Um dos caminhos encontrados pelos gestores na busca de novas aprendizagens é o da educação formal (cursos, workshops, eventos, dentre outras atividades). Preocupados com sua colocação profissional, identificam os 
programas de MBA (Master in Business Administration - voltados para a educação gerencial), como uma via para atuarem em um mundo globalizado, que abre inúmeras oportunidades para os mais qualificados (WOOD JR; PAES DE PAULA, 2004). Diversas críticas, no entanto, vêm alvejando o ensino em Administração e as aprendizagens possibilitadas por seus programas, fundamentadas em diferentes visões sobre o papel dos gestores. O debate crítico coloca os gestores no papel de vilões pelo impacto de seu trabalho na vida das pessoas e os responsabiliza por problemas psíquicos, sociais e ecológicos oriundos, pelo menos em parte, de sua atividade profissional (REYNOLDS, 1998). Paradoxalmente, a crescente precariedade do mundo do trabalho os posiciona também como vítimas que sofrem insegurança quanto à sua própria colocação profissional (TONELLI, 2005). Estes dois enfoques têm um ponto em comum: a necessidade de novas aprendizagens. O primeiro destaca a importância de aprendizagens que ampliem a consciência quanto às possíveis consequências oriundas da atividade profissional dos gestores sobre a sociedade, o meio ambiente e eles próprios. O segundo ressalta a pressão que os gerentes sofrem para obtenção de novas aprendizagens a fim de tentarem "garantir" sua empregabilidade por meio de educação e do desenvolvimento profissional. Esses pressupostos sobre o papel gerencial dão origem a visões distintas acerca da aprendizagem gerencial sob o enfoque da educação em administração.

As correntes que criticam a educação em administração podem ser aglutinadas em dois grandes grupos. Um dos grupos está representado pela corrente que questiona a eficácia dos programas, acusando-os de não capacitarem para a gestão, embora façam crer que capacitem, ela é originária principalmente dos estudos de Henry Mintzberg e colaboradores. O autor propõe um modelo alternativo aos programas de MBA cujos pilares são: a utilização da experiência profissional dos gestores; a vivência internacional; o uso de uma pedagogia que envolve grande interação entre estudantes; uma disposição física especial para as salas de aula (WOOD JR; PAES DE PAULA, 2004).

Percebe-se, nesta corrente, a ênfase na aprendizagem experiencial (KOLB, 1997; SCHÖN, 1983), baseada nas vivências dos gestores, além do destaque para a importância das interações no processo de aprendizagem. Essa visão pressupõe que a aprendizagem ocorre somente quando uma pessoa é capaz de refletir sobre suas ações, reorganizando e reconstruindo suas experiências. O conceito de reflexão, no sentido de tornar consciente e produtiva uma experiência dotando-a de significado, é central para a teoria da aprendizagem experiencial, amplamente divulgada e aplicada no campo de estudos gerenciais (REYNOLDS, 1998).

Schön (1983) concebe a reflexão como um processo que envolve a busca, o teste e a avaliação de entendimentos intrínsecos à experiência, à prática profissional. $\mathrm{O}$ autor observa duas possibilidades de responder a algum elemento surpresa em experiências rotineiras: (a) refletindo sobre $a$ ação retrospectivamente, após o fato ou por uma pausa para pensar no meio da ação, desconectando a reflexão da ação presente; (b) pela reflexão-na-ação, refletindo no meio da ação, pensando para dar forma ao que está sendo realizado, a fim de interferir na ação em andamento, aspecto essencial para lidar com situações problemáticas envolvidas nas práticas de trabalho diárias dos gestores (SCHON, 2000).

O segundo grupo que tece críticas à educação em administração é representado por autores filiados aos Critical Management Studies. Paes de Paula e Rodrigues (2006, p.4) sintetiza a visão de seus principais idealizadores: (a) a ideia de que as organizações são necessárias, naturais, racionais e autoevidentes e não fruto de um complexo processo sócio-histórico; (b) a visão de que os interesses administrativos são universais e de que não há interesses conflitantes; (c) o domínio da instrumentalidade e da competição no imaginário organizacional. Wood Jr. e Paes de Paula (2004) identificam ainda outras críticas: excessiva redução da complexidade dos fenômenos estudados; tendência à acentuação da instrumentalidade, levando os estudantes a aprenderem reprodução de técnicas e não realização de diagnósticos; menor efetividade de conteúdos e métodos; reduzido incentivo à autonomia e ao autodidatismo; processo de "mercadorização" do ensino.

Segundo Reynolds (1998), a educação gerencial deveria estimular o questionamento das forças políticas e sociais que geram o contexto do trabalho desses profissionais, ao invés de simplesmente ajustá-los às instituições, aspecto favorecido pela reflexão crítica. O crescimento, na literatura, do interesse sobre a aprendizagem de gestores em uma perspectiva mais crítica é, no entanto, mais recente e raramente atinge o meio gerencial ou o campo da educação de gestores. Essa perspectiva refere-se ao conceito de reflexão crítica como uma avaliação histórica e contextual de pressupostos sociais e políticos, a qual se distingue de outras 
formas de reflexão por: a) um interesse no questionamento de pressupostos; b) foco social ao invés de individual; c) atenção especial à análise de relações de poder (REYNOLDS, 1998).

Percebe-se, pois, que as duas vertentes que criticam a educação gerencial destacam o papel da reflexão nos processos de aprendizagem gerencial, entretanto, a segunda vertente valoriza especialmente a reflexão crítica. Cunliffe (2004) considera a possibilidade de dotar uma experiência de sentido por intermédio da reflexão de dois modos: (a) pela análise reflexiva: como um processo analítico, objetivo, pelo qual se constrói o entendimento de uma situação pelo teste de entendimentos intuitivos sobre um fenômeno vivenciado, este processo evidencia semelhanças com a noção de reflexão-na-ação de Schön (1983); (b) pelo questionamento reflexivo crítico, que envolve a exposição de contradições, dúvidas, dilemas, possibilidades, buscando iluminar ideologias e pressupostos tácitos, evidenciando similaridade ao conceito de reflexão crítica, baseado no pressuposto de que existem realidades construídas, múltiplas e subjetivas.

Verifica-se, assim, a partir da visão dos autores abordados nessa seção, o papel central da reflexão e da reflexão crítica para o processo de aprendizagem gerencial. Esta conclusão é corroborada pela avaliação da produção científica na área de ensino em Administração dos anais do Encontro Nacional da Associação Nacional dos Programas de Pós-Graduação em Administração, de 2002 a 2005, realizada por Closs et al. (2006). Os resultados deste estudo apontam para a necessidade de maior reflexão nos estudos gerenciais e revelam a carência de reflexão crítica. Entre as críticas levantadas pelos autores brasileiros, destacam-se a carência de uma educação problematizadora, de caráter reflexivo, voltada para a inserção crítica dos indivíduos na sociedade; a ênfase excessiva em técnicas; a ausência de preocupação com valores e atitudes.

\section{Estudos Desenvolvidos no Brasil acerca do Processo de Aprendizagem Gerenclal}

A aprendizagem gerencial é um processo dinâmico e situado, ou seja, é um processo social imbricado em um contexto organizacional e social, quer em ambientes formais ou informais, nos quais os indivíduos estão inseridos (ANTONELLO, 2004). O campo de pesquisa acerca dos processos de aprendizagem gerencial à luz da abordagem da aprendizagem social ainda é incipiente no Brasil (MORAES; SILVA; CUNHA, 2004).

Nesta seção, apresenta-se a análise de dados obtidos a partir de levantamento de pesquisas empíricas, desenvolvidas no Brasil, que buscaram investigar como ocorrem os processos de aprendizagem de indivíduos que ocupam a função gerencial, ou seja, que tentaram responder a questão "como os gerentes aprendem". Embora os estudos não tragam resultados conclusivos, foi possível identificar aspectos relevantes para o debate neste campo teórico.

Consideraram-se, para o levantamento, as publicações realizadas no Brasil entre os anos de 2000 e 2006 , encontradas junto à base de teses e dissertações da Capes e selecionadas a partir das palavras-chave aprendizagem e aprendizagem gerencial. Na primeira busca, foram identificados alguns estudos que não disponibilizavam seu texto na íntegra. Procurou-se, então, identificar artigos, junto a periódicos e anais de congressos conceito 'A' (nível nacional), que pudessem ser produto destes estudos. Identificou-se apenas um artigo desenvolvido por Silva, Rebelo e Cunha (2006), fruto de pesquisa independente dos autores.

A partir da leitura dos trabalhos selecionados pelo critério especificado, inicialmente realizou-se a análise das questões de pesquisa e dos objetivos propostos em cada um dos estudos sobre aprendizagem gerencial. A seguir, o esforço foi no sentido de identificar a abordagem metodológica utilizada pelos estudos, com o intuito de visualizar os caminhos adotados pelos pesquisadores para conduzir suas investigações sobre o tema. Buscou-se, então, identificar e sintetizar os principais achados de cada um dos trabalhos, destacando-se suas contribuições para o aprofundamento dos estudos no campo da aprendizagem gerencial. Por fim, foram identificadas as sugestões delineadas pelos pesquisadores para estudos futuros, no sentido de iluminar perspectivas e direcionamentos para o desenvolvimento de novos estudos sobre esta temática.

O Quadro 1 sintetiza os dados coletados a partir destes estudos. 


\section{Quadro 1 - Estudos sobre aprendizagem gerencial realizados por pesquisadores brasileiros entre 2000 e 2006}

\begin{tabular}{|c|c|c|c|}
\hline $\begin{array}{c}\text { Autor/ano/ } \\
\text { Tipo trabalho }\end{array}$ & $\begin{array}{c}\text { Objetivo do estudo/ } \\
\text { Abordagem Metodológica }\end{array}$ & Principais achados & Sugestões para estudos futuros \\
\hline $\begin{array}{l}\text { Gottwald, G. } \\
\text { (2001) } \\
\text { Dissertação } \\
\text { UFSC }\end{array}$ & $\begin{array}{l}\text { Compreender o processo de } \\
\text { aprendizagem de executivos da } \\
\text { VW/Audi } \\
\text { Abordagem metodológica: } \\
\text { estudo de caso qualitativo }\end{array}$ & $\begin{array}{l}\text { - o que mais propicia aprendizagem são contextos informais (responsabilidades } \\
\text { novas e confrontos com contextos desconhecidos); } \\
\text { - treinamentos de caráter formal contribuem pouco para a aprendizagem; } \\
\text { - relacionamentos com time são importantes para aprendizagem; } \\
\text { - a cultura organizacional é aprendida por reflexão e assimilação; especialmente } \\
\text { por vivência na matriz; } \\
\text { - a organização é responsável pela maioria das intenções de aprendizagem; } \\
\text { - tendência a refletir mais após ações (como forma de aprendizagem) mas não } \\
\text { refletem criticamente; } \\
\text { - ambiente com liberdade para tomada de ações e decisões favorece a } \\
\text { aprendizagem. }\end{array}$ & $\begin{array}{l}\text { - quais os fatores que influenciam no processo de } \\
\text { aprendizagem e em que profundidade; } \\
\text { - qual a importância da cultura organizacional no } \\
\text { conteúdo e no processo de aprendizagem de } \\
\text { executivos; } \\
\text { - qual a relação entre o quê e como executivos } \\
\text { aprendem. }\end{array}$ \\
\hline $\begin{array}{l}\text { Possamai, F. } \\
\quad(2005) \\
\text { Tese UFSC }\end{array}$ & $\begin{array}{l}\text { Compreender o processo da } \\
\text { aprendizagem de executivos de } \\
\text { uma empresa e sua relação com a } \\
\text { cultura da organização } \\
\text { Pesquisados: } \\
7 \text { executivos da Tigre } \\
\text { Abordagem pesquisa: } \\
\text { qualitativa básica }\end{array}$ & $\begin{array}{l}\text { - aprendizagem dos executivos ocorre no ambiente de trabalho, implementando } \\
\text { mudanças de ordem técnica e comportamental; } \\
\text { - a aprendizagem é eminentemente informal, autodirecionada, continuada, com } \\
\text { foco no diariamente e estreitamente ligado à cultura da organização. }\end{array}$ & $\begin{array}{l}\text { - uso de diferentes metodologias de pesquisa sobre } \\
\text { a cultura; } \\
\text { - estudar relações de poder que se estabelecem no } \\
\text { interior das organizações; } \\
\text { - estudos em outras regiões; } \\
\text { - influência da cultura na aprendizagem de gestores } \\
\text { com perfil diferente dos pesquisados (engenheiros). }\end{array}$ \\
\hline $\begin{array}{l}\text { Grohmann, M. } \\
\text { (2004) } \\
\text { Tese UFSC }\end{array}$ & $\begin{array}{l}\text { Compreender qual o impacto que } \\
\text { a educação formal, através de um } \\
\text { curso de pós-graduação, tem no } \\
\text { processo de aprendizagem } \\
\text { gerencial } \\
\text { Pesquisados: } 8 \text { gerentes com } \\
\text { pouca experiência } \\
\text { Abordagem metodológica: } \\
\text { fenomenologia hermenêutica }\end{array}$ & $\begin{array}{l}\text { - os gerentes aprenderam por motivos pessoais e profissionais; } \\
\text { - os gerentes utilizam diferentes formas de aprendizagem, com destaque para a } \\
\text { aprendizagem através da ação, seguida dos relacionamentos sociais; } \\
\text { - os gerentes aprenderam a importância das habilidades humanas e de } \\
\text { conhecimentos voltados para relacionamentos; } \\
\text { - os gerentes fizeram o curso para adquirir melhores conhecimentos para } \\
\text { atividade profissional e pela vontade de aprender; } \\
\text { - as principais formas utilizadas para aprendizagem no curso foram: ler e estudar, } \\
\text { ouvir professores e debates; aprenderam a dar maior valor às habilidades técnicas } \\
\text { e descobriram novos conhecimentos voltados às tarefas; } \\
\text { - a educação formal teve como principais reflexos na aprendizagem: ampliação } \\
\text { em algumas de suas habilidades e valorização de outras; aquisição de novos } \\
\text { conhecimentos (principalmente voltados às tarefas) e poucas mudanças de } \\
\text { atitude. }\end{array}$ & $\begin{array}{l}\text { - novos estudos para compreender fenômeno da } \\
\text { aprendizagem; } \\
\text { - processos de aprendizagem mais sutis; } \\
\text { - estudos centrados no aprendiz; percepções dos } \\
\text { alunos sobre cursos; } \\
\text { - reflexos da experiência profissional na } \\
\text { aprendizagem; } \\
\text { - evolução da aprendizagem durante cursos; } \\
\text { - influência da reflexão e da reflexão crítica na } \\
\text { aprendizagem; } \\
\text { - relação da aprendizagem situada com } \\
\text { manutenção de poder/manipulação. }\end{array}$ \\
\hline
\end{tabular}




\begin{tabular}{|c|c|c|c|}
\hline $\begin{array}{c}\text { Autor/ano/ } \\
\text { Tipo trabalho }\end{array}$ & $\begin{array}{c}\text { Objetivo do estudo/ } \\
\text { Abordagem Metodológica }\end{array}$ & Principais achados & Sugestões para estudos futuros \\
\hline $\begin{array}{c}\text { Lucena, E. } \\
\text { (2001) } \\
\text { Tese UFSC }\end{array}$ & $\begin{array}{l}\text { Compreender a natureza da } \\
\text { aprendizagem de gerentes- } \\
\text { proprietários do setor de varejo } \\
\text { de vestuário de Florianópolis } \\
\text { Pesquisados: } 10 \text { gerentes- } \\
\text { proprietários de MPEs } \\
\text { Abordagem pesquisa: } \\
\text { qualitativa básica } \\
\text {. }\end{array}$ & $\begin{array}{l}\text { - motivados a aprender devido às demandas do trabalho (enfrentar } \\
\text { concorrência, superar adversidades do negócio, necessidades de } \\
\text { adquirir certos conhecimentos), por casualidades e para obter } \\
\text { recompensas em suas atividades; } \\
\text { - aprendiam por meio de relacionamentos sociais (com determinados } \\
\text { familiares, sócios, colegas); } \\
\text { - a maior parcela da aprendizagem profissional derivava da prática e da } \\
\text { reflexão em questões de trabalho; } \\
\text { - os aprendizes eram influenciados pela mídia e pelo contexto de } \\
\text { trabalho; } \\
\text { - os conteúdos assimilados compreendiam o nível individual assim } \\
\text { como o organizacional }\end{array}$ & $\begin{array}{l}\text { - estudo sobre como profissionais que trabalham em firmas } \\
\text { especializadas no desenvolvimento de recursos humanos } \\
\text { contribuem para o desenvolvimento de seus clientes, } \\
\text { considerando não apenas as opiniões dos consultores das } \\
\text { empresas de recursos humanos, mas também as perspectivas } \\
\text { dos aprendizes envolvidos. }\end{array}$ \\
\hline $\begin{array}{l}\text { Moraes, L. } \\
\text { (2000) } \\
\text { Dissertação } \\
\text { UFSC }\end{array}$ & $\begin{array}{l}\text { Investigar o processo de } \\
\text { aprendizagem de gerentes em } \\
\text { organizações hospitalares } \\
\text { Abordagem metodológica: } \\
\text { estudo de caso qualitativo }\end{array}$ & $\begin{array}{l}\text { - aprendizagem gerencial é um processo dinâmico, ocorre ao longo da } \\
\text { trajetória, com ajustes em estágios de transição, dependendo das } \\
\text { demandas e desafios do trabalho e das dimensões: individual (história } \\
\text { de vida e padrões culturais e psicológicos), do trabalho (a organização, } \\
\text { sua cultura e as interações entre membros) e social (aspectos políticos, } \\
\text { econômicos e sociais que influenciam as atividades da organização e a } \\
\text { ação do indivíduo); } \\
\text { - a aprendizagem dos executivos transcende a classificação formal e } \\
\text { informal; a maior parte das aprendizagens foi incidental; } \\
\text { - formas de aprendizagem: projetos de aprendizagem, compartilhar } \\
\text { relacionamentos, atualização profissional, reflexão, observação, ação e } \\
\text { mudança de consciência (central por contribuir para atualizar a } \\
\text { estratégia empresarial e a transformação pessoal. }\end{array}$ & $\begin{array}{l}\text { - aprendizagens que transcendam as classificações formal e informal; } \\
\text { - como os aspectos sociais e a reflexão integram a dinâmica da } \\
\text { aprendizagem; } \\
\text { - mudança de consciência como aprendizagem; } \\
\text { - novas formas de ensino na educação, T e D; } \\
\text { - influência da cultura na aprendizagem gerencial } \\
\text { - transferência da aprendizagem individual para a organização }\end{array}$ \\
\hline $\begin{array}{c}\text { Antonello, C. } \\
\text { (2004) } \\
\text { Tese PPGA/ } \\
\text { UFRGS }\end{array}$ & $\begin{array}{l}\text { Identificare analisar a contribuição } \\
\text { de processos de aprendizagem } \\
\text { coletivos formais e informais no } \\
\text { desenvolvimento de competências } \\
\text { gerenciais, a partir das percepções } \\
\text { de participantes de programas de } \\
\text { especialização e mestrado } \\
\text { profissional em administração } \\
\text { realizados no âmbito da UFRGS. } \\
\text { Abordagem pesquisa: } \\
\text { exploratória, longitudinal, qualitativa } \\
\text { comanálise de dados pela } \\
\text { grounded theory }\end{array}$ & $\begin{array}{l}\text { - resultados destacam a importância das práticas de trabalho e a } \\
\text { possibilidade de sua articulação aos cursos de formação gerencial no } \\
\text { desenvolvimento de competências numa dimensão individual e } \\
\text { coletiva, a partir da abordagem da aprendizagem experiencial; } \\
\text { - as aprendizagens formal e informal estão indissoluvelmente inter- } \\
\text { relacionaadas; } \\
\text { - desenvolvimento de competências a partir de seis elementos: reflexão; } \\
\text { diálogo; autodesenvolvimento; aprendizagem experiencial; significado } \\
\text { do trabalho; espaço organizacional de aprendizagem; } \\
\text { - importância dos microprocessos de aprendizagem e das interações } \\
\text { dos indivíduos nos pequenos grupos para compreensão da articulação } \\
\text { entre os níveis individual e organizacional de aprendizagem. }\end{array}$ & $\begin{array}{l}\text { - estudar a própria taxonomia das formas de aprendizagemidentificadas: validar a } \\
\text { taxonomia; formas adicionais de aprendizagem; quais tipos de competências são } \\
\text { desenvolvidas em cadauma destas formas; } \\
\text { - se hárelação entre os tipos de competência desenvolvidas em cadaumdos ciclos } \\
\text { de aprendizagem organizacional equais são eles. } \\
\text { - aprofundar proposta de aprendizagem organizacional por intemíveis, pela } \\
\text { disseminação epelo compartilhamentode competências; } \\
\text { - validar instrumentos para identificação de estilos de } \\
\text { aprendizagem em contexto brasileiro; } \\
\text { - aprofundar o papel dos seis elementos de aprendizagem identificados, } \\
\text { especialmente: o autodesenvolvimento; o significado do trabalho no desenvolvi- } \\
\text { mento de competênciase espaço organizacional para aprendizagem; } \\
\text { - questão de formação deComunidades dePrática no ambiente organizacional. }\end{array}$ \\
\hline
\end{tabular}




\begin{tabular}{|c|c|c|c|}
\hline $\begin{array}{c}\text { Autor/ano/ } \\
\text { Tipo trabalho }\end{array}$ & $\begin{array}{c}\text { Objetivo do estudo/ } \\
\text { Abordagem Metodológica }\end{array}$ & Principais achados & Sugestões para estudos futuros \\
\hline $\begin{array}{l}\text { Bitencourt, C. } \\
\text { (2001) } \\
\text { Tese PPGA/ } \\
\text { UFRGS }\end{array}$ & $\begin{array}{l}\text { Identificar e caracterizar a gestão de } \\
\text { competências gerenciais e analisar a } \\
\text { contribuição de elementos de } \\
\text { Aprendizagem Organizacional neste } \\
\text { processo, tomando-se por base a } \\
\text { investigação e exploração de práticas de } \\
\text { gestão em organizações do RS/Brasil e } \\
\text { Queensland/Austrália. } \\
\text { Participantes: gestores de } 6 \text { empresas, } 3 \\
\text { de cada país. } \\
\text { Abordagem metodológica: } \\
\text { estudo de caso qualitativo }\end{array}$ & $\begin{array}{l}\text { - importância das práticas informais e das experiências que envolvem } \\
\text { outros ambientes, não apenas o organizacional; } \\
\text { - importância da construção de uma consciência social; } \\
\text { - elementos que dificultam desenvolvimento de competências: volume de } \\
\text { trabalho e burocracia do sistema; abstração e excesso de planejamento } \\
\text { versus ação; } \\
\text { - situações significativas para formação e desenvolvimento: } \\
\text { autodesenvolvimento; relacionamento interpessoal; desafios; satisfação } \\
\text { social; experiência voltada a modelos de liderança; práticas do dia-a-dia; } \\
\text { vivência no exterior; papel da universidade; sistemas de gestão e projetos } \\
\text { que estimulam a visão processual e a equipe multifuncional; importância } \\
\text { da família; } \\
\text { - importância da reflexão em ação (questionamento constante, busca de } \\
\text { melhorias contínuas). }\end{array}$ & $\begin{array}{l}\text { - experiências pessoais e de situações que extrapolam } \\
\text { o ambiente organizacional e que envolvem a questão } \\
\text { ética, valores e responsabilidade social; } \\
\text { - emoções e afetividade das pessoas, destacadas como } \\
\text { fator fundamental para o desenvolvimento e formação } \\
\text { de gestores; } \\
\text { - articulação entre políticas de ensino e } \\
\text { profissionalização; } \\
\text { - papel decisivo do diretor-superintendente ou CEO } \\
\text { na definição de estratégias e práticas que estimulam o } \\
\text { desenvolvimento de competências; } \\
\text { - aprofundamento de elementos como práticas } \\
\text { formais (enfatizadas nas empresas australianas) } \\
\text { versus práticas informais (no Brasil). }\end{array}$ \\
\hline $\begin{array}{c}\text { Silva, A.; } \\
\text { Rebelo, L.; } \\
\text { Cunha, C. } \\
\text { (2006) } \\
\text { Artigo } \\
\text { Enanpad }\end{array}$ & $\begin{array}{l}\text { Compreender o processo de } \\
\text { aprendizagem sob a perspectiva da } \\
\text { experiência vivida - como ocorreu o } \\
\text { processo de transformação da passagem } \\
\text { de empregados a dirigentes vivenciado } \\
\text { por dois } 2 \text { sócios-proprietários. } \\
\text { Abordagem metodológica: } \\
\text { fenomenologia hermenêutica }\end{array}$ & $\begin{array}{l}\text { - existência de cinco dimensões de experiências vividas que influenciaram } \\
\text { a aprendizagem: a família, a escola, a comunidade, a vida como } \\
\text { empregado e a vida como gerente; } \\
\text { - esses fatores contribuem para o desenvolvimento das habilidades e } \\
\text { atitudes necessárias no processo de aprendizagem gerencial, } \\
\text { direcionando decisões e ações dos gerentes durante sua vida; } \\
\text { - no processo de aprendizagem houve uma transformação nas } \\
\text { perspectivas de significados e esquemas; } \\
\text { - o processo de reflexão crítica esteve presente nas ações dos gerentes; } \\
\text { uma das características marcantes do processo de transformação foi a } \\
\text { capacidade de ambos realizarem a "reflexão-na-ação"; } \\
\text { - influência marcante dos valores de base, centrados na família. }\end{array}$ & $\begin{array}{l}\text { - não constam sugestões para estudos futuros no } \\
\text { artigo. }\end{array}$ \\
\hline $\begin{array}{l}\text { Leite, I.; } \\
\text { Godoy, A.; } \\
\text { Antonello, C. } \\
\text { (2006) } \\
\text { Artigo } \\
\text { Aletheia } \\
\text { Leite, I } \\
\text { (2005) } \\
\text { Dissertação } \\
\text { Univeridade } \\
\text { Presbiteriana } \\
\text { Mackenzie. }\end{array}$ & $\begin{array}{l}\text { Compreender como gerentes aprendem o } \\
\text { exercício da função gerencial por meio } \\
\text { da sua experiência. } \\
\text { Participantes: gerentes gerais de agências } \\
\text { de bancos de varejo } \\
\text { Abordagem metodológica: } \\
\text { qualitativa; análise de conteúdo para } \\
\text { analisar dados. }\end{array}$ & $\begin{array}{l}\text { - aprendem habilidades gerenciais com experiências vivenciadas, não } \\
\text { apenas nas marcantes, mas também em atividades corriqueiras; } \\
\text { - desafios forçam gerentes a experimentar novos comportamentos e } \\
\text { consequiências, levando ao aprendizado pela experiência; } \\
\text { - entre as formas de aprender pela experiência destacam-se a observação, } \\
\text { as experiências contadas por outros e a aprendizagem por tentativa e erro, } \\
\text { o que pode implicar comprometimento da inovação e da criatividade na } \\
\text { busca de alternativas para solução de problemas; foram enfatizadas ainda } \\
\text { a trajetória profissional em cargos diferentes e o treinamento explícito; } \\
\text { - as principais fontes de aprendizagem incluem a família, representada } \\
\text { pelo pai, os colegas de trabalho e superiores hierárquicos. }\end{array}$ & $\begin{array}{l}\text { - pesquisar efeitos das características do trabalho em } \\
\text { combinação ao comportamento de aprendizagem na } \\
\text { carreira gerencial. }\end{array}$ \\
\hline
\end{tabular}




\begin{tabular}{|c|c|c|c|}
\hline $\begin{array}{c}\text { Autor/ano/ } \\
\text { Tipo trabalho }\end{array}$ & $\begin{array}{c}\text { Objetivo do estudo/ } \\
\text { Abordagem Metodológica }\end{array}$ & Principais achados & Sugestões para estudos futuros \\
\hline $\begin{array}{l}\text { Cunha, M. } \\
\text { (2003) } \\
\text { Tese UFSC }\end{array}$ & $\begin{array}{l}\text { Compreender as experiências } \\
\text { vividas por gerentes, em uma } \\
\text { empresa do ramo de alimentos, } \\
\text { situada no estado do RS, com } \\
\text { relação às mudanças } \\
\text { organizacionais. } \\
\text { Participantes: } 10 \text { gerentes da } \\
\text { empresa } \\
\text { Abordagem metodológica: } \\
\text { fenomenologia hermenêutica }\end{array}$ & $\begin{array}{l}\text { - os gerentes precisam atuar como facilitadores de mudanças, envolvendo a } \\
\text { capacidade de influenciar, favorecer motivação e autoconfiança; ter visão } \\
\text { abrangente; dividir responsabilidades e compartilhar poder; } \\
\text { - medo, especialmente em situações de instabilidade, de ser incapaz de } \\
\text { corresponder às novas demandas, adquirir novos comportamentos; } \\
\text { - importância da inclusão de objetivos pessoais aos organizacionais; } \\
\text { - a experiência de mudança provoca crescimento os preparando para enfrentar } \\
\text { diversas situações; } \\
\text { - valorização de relacionamentos interpessoais; } \\
\text { - o questionamento de práticas revela-se importante; escolhas implicam } \\
\text { assumir responsabilidades, perdas e riscos; } \\
\text { - importância do trabalho realizado em equipe; } \\
\text { - oportunidade de conhecer os outros e a si próprio; } \\
\text { - a mudança envolve aprendizado contínuo; autoconsciência. }\end{array}$ & $\begin{array}{l}\text { - aprofundar temas que emergiram da } \\
\text { investigação; } \\
\text { - focalizar outros atores envolvidos nos } \\
\text { processos de mudança, tais como dirigentes de } \\
\text { empresas ou funcionários. }\end{array}$ \\
\hline $\begin{array}{l}\text { Roglio, K. } \\
\text { (2006) } \\
\text { Tese UFSC }\end{array}$ & $\begin{array}{l}\text { Desenvolver o conceito de } \\
\text { executivo reflexivo e identificar } \\
\text { de que forma programas de MBA } \\
\text { Executivo influenciam o } \\
\text { desenvolvimento de executivos } \\
\text { reflexivos. } \\
\text { Participantes: profissionais } \\
\text { realizando um MBA executivo } \\
\text { em um programa conceituado } \\
\text { com um dos } 5 \text { melhores do } \\
\text { mundo } \\
\text { Abordagem metodológica: estudo } \\
\text { de caso qualitativo }\end{array}$ & $\begin{array}{l}\text { - a prática reflexiva é formada pelas interrelações entre o pensamento } \\
\text { conectivo, o pensamento crítico e o pensamento introspectivo; essa prática } \\
\text { estimula o processo de aprendizagem do executivo; no seu processo decisório, } \\
\text { a aprendizagem gerada pela prática reflexiva promove a criação de uma } \\
\text { configuração organizacional equilibrada, que concilia a visão organizacional } \\
\text { estratégica com a dinâmica das relações interpessoais e a eficácia dos } \\
\text { processos organizacionais. } \\
\text { - lacuna entre o reconhecimento da relevância da prática reflexiva e a sua } \\
\text { aplicação nos processos decisórios. Por isso, foram identificadas possibilidades } \\
\text { para o exercício da prática reflexiva, que possibilitam ao executivo fazer a } \\
\text { escolha consciente de incorporar a prática reflexiva a seu processo decisório e } \\
\text { compartilhar a aprendizagem resultante em toda a organização; } \\
\text { - MBA Executivo configura-se como uma opção concreta para difundir o } \\
\text { conceito de executivo reflexivo e proporcionar o exercício sistemático e } \\
\text { continuado da prática reflexiva. Elementos relevantes para o desenvolvimento } \\
\text { dessa prática nesses programas são: atuação dos professores como } \\
\text { profissionais reflexivos; metodologias educacionais baseadas na interação } \\
\text { entre experiências primárias e secundárias; a ênfase sobre o processo de } \\
\text { compartilhar experiências e o diálogo sobre elas; as equipes de aprendizagem. }\end{array}$ & $\begin{array}{l}\text { - mecanismos que possibilitem a prática } \\
\text { reflexiva; comparação de executivos no início } \\
\text { e no término de um programa de MBA; } \\
\text { natureza da prática reflexiva realizada } \\
\text { coletivamente; estratégias de transferência do } \\
\text { conhecimento adquirido no MBA para a } \\
\text { realidade da sua vida pessoal e profissional; } \\
\text { características específicas da prática reflexiva; } \\
\text { existência (ou não) de correlações entre o } \\
\text { exercício da prática reflexiva, características } \\
\text { individuais e organizacionais; diferenças no } \\
\text { modo dos executivos interpretarem e } \\
\text { vivenciarem o conceito de executivo } \\
\text { reflexivo; estudo no contexto brasileiro. } \\
\text { - múltiplas entrevistas com cada executivo; } \\
\text { diferentes fontes de informação, como a } \\
\text { inclusão de outros programas de MBA para } \\
\text { análises comparativas; variações na forma } \\
\text { como os executivos vivenciam a prática } \\
\text { reflexiva com base na fenomenografia. }\end{array}$ \\
\hline
\end{tabular}

Fonte: elaborado pelas autoras a partir de levantamento de publicações nacionais sobre o tema aprendizagem gerencial 
Destaca-se, primeiro, o volume reduzido de publicações sobre o tema, dada a importância dos gestores como atores sociais; a relevância da aprendizagem na sociedade atual; as crescentes demandas exigidas desses profissionais, que implicam aprendizagens. Desperta a atenção, também, o fato de que todos os trabalhos adotaram a epistemologia construtivista, utilizaram abordagens metodológicas de natureza qualitativa e evidenciaram preocupação em considerar a natureza processual do fenômeno da aprendizagem. Os métodos variam entre estudo de caso, fenomenologia hermenêutica e pesquisa qualitativa básica, esta última apresentando variações entre os métodos de análise de dados. Os gerentes, executivos e gerentes-proprietários pesquisados atuam em organizações de diferentes segmentos, lotados em estados das regiões sudeste e sul do país. Apenas um dos estudos pesquisou gerentes de outro país. Identificou-se que os pesquisados pertencem a organizações de diferentes segmentos como o industrial (ex.: automobilístico, de alimentos) e o de serviços (ex.: hospitalar, financeiro) e abrangem gerentes-proprietários (ex.: do setor do varejo de vestuário).

A influência da educação formal está retratada no estudo de Grohman (2004), que buscou compreender o impacto de um curso MBA no processo de aprendizagem gerencial; no estudo realizado por Antonello (2004), que analisou a contribuição de processos de aprendizagem coletivos formais e informais no desenvolvimento de competências gerenciais, pesquisando participantes de cursos de especialização e mestrado profissional; no estudo desenvolvido por Roglio (2006), que visava identificar de que forma programas de MBA Executivo influenciam o desenvolvimento de executivos reflexivos.

Dentre os relacionamentos, destaca-se o papel da família como uma das principais fontes de aprendizagem e constituinte de valores (LEITE; GODOY; ANTONELLO, 2006; SILVA; REBELO; CUNHA, 2006), aspecto também apontado nos estudos de Lucena (2000) e Bitencourt (2001). Gottwald (2001), Moraes (2000) e Antonello (2004) salientam a importância para a aprendizagem dos relacionamentos entre membros na organização; Roglio (2006) dá destaque ao papel das equipes de aprendizagem no programa de MBA estudado.

Aspectos relacionados à reflexão são constantes nos estudos sobre aprendizagem gerencial desenvolvidos pelos pesquisadores brasileiros. Gottwald (2001) diz que a cultura organizacional é aprendida por reflexão e assimilação e que os gestores pesquisados tendem a refletir mais após as ações, mas não criticamente. Bitencourt (2001) percebe, entre os gestores pesquisados, a importância da reflexão na ação, por meio de questionamentos constantes e da busca de melhorias contínuas. Silva, Rebelo e Cunha (2006), entre os sóciosproprietários estudados, verificaram a presença da reflexão crítica nas ações dos gestores, uma das características marcantes em seu processo de transformação foi a capacidade de refletirem na ação. Moraes (2000), Lucena (2001) e Antonello (2004) destacam ainda o papel da reflexão como forma de aprendizagem. De acordo com Roglio (2006), a prática reflexiva, formada pelas inter-relações entre o pensamento conectivo, o pensamento crítico e o pensamento introspectivo, estimula o processo de aprendizagem do executivo.

Quanto ao caráter formal da aprendizagem, Gottwald (2001) observa que programas de treinamento na organização contribuem pouco para a aprendizagem. Grohmann (2004) identifica que a educação formal teve como principais reflexos na aprendizagem a ampliação de algumas de suas habilidades; a valorização de outras; a aquisição de novos conhecimentos; mas poucas mudanças de atitude. Leite, Godoy e Antonello (2006), no entanto, destacam o treinamento explícito como uma das formas de aprender utilizadas pelos gestores. Entre as situações significativas para a sua formação e desenvolvimento, Bitencourt (2004) identifica o papel da universidade e Silva, Rebelo e Cunha (2006) destacam o papel da escola entre as dimensões de experiências vividas que influenciaram a aprendizagem dos sócios-gerentes pesquisados. Roglio (2006) menciona que o MBA Executivo configura-se como uma opção concreta para proporcionar o exercício sistemático e continuado da prática reflexiva.

Antonello (2004) ressalta a possibilidade de articulação das práticas de trabalho com os cursos de formação gerencial e salienta que aprendizagem formal e informal estão indissoluvelmente articuladas. Moraes (2000), nesse sentido, visualiza que a aprendizagem de executivos transcende a classificação formal e informal e observa que a maior parte das aprendizagens identificadas em seu estudo foram incidentais. A importância do autodesenvolvimento para a aprendizagem de gestores foi também destacada pelos pesquisados (BITENCOURT, 2001; ANTONELLO, 2004; POSSAMAI, 2005). 
A partir dos trabalhos realizados, os pesquisadores brasileiros trazem sugestões para estudos futuros. A seguir são explorados os mais relevantes para o presente estudo.

Gottwald (2001) e Grohmann (2004) sugerem novos estudos para compreender o fenômeno da aprendizagem. Bitencourt (2001) propõe o aprofundamento das práticas formais (enfatizadas nas empresas australianas) versus práticas informais (marcantes no Brasil). Moraes (2000) recomenda o estudo de aprendizagens que transcendam a classificação formal e informal, uma vez que constatou, em seu estudo, a presença marcante de aprendizagens incidentais. Antonello (2004) propõe o estudo e a validação da taxonomia das formas de aprendizagem identificadas em seu estudo e de formas adicionais de aprendizagem. Antonello (2004) ainda sugere o aprofundamento do papel dos elementos de aprendizagem identificados, especialmente o autodesenvolvimento, o significado do trabalho no desenvolvimento de competências e o espaço organizacional para aprendizagem. A importância de compreender a influência da cultura na aprendizagem de gestores com perfil diferente dos pesquisados é destacada por Possamai (2005).

Roglio (2001) propõe o aprofundamento da compreensão sobre a prática reflexiva. A investigação sobre o papel da reflexão e a influência da reflexão crítica para a aprendizagem, além da mudança de consciência como aprendizagem são sugeridas por Grohmann (2004) e Moraes (2000). Bitencourt (2001) propõe pesquisas envolvendo experiências pessoais e de situações que extrapolam o ambiente organizacional, envolvendo a questão ética, valores e responsabilidade social, além do estudo acerca das emoções e da afetividade das pessoas como fatores essenciais para o desenvolvimento e a formação de gestores.

Considerando os principais achados dos estudos e as sugestões de pesquisa elaboradas pelos pesquisadores que trabalharam com a questão da aprendizagem de gestores, verifica-se que o processo reflexivo tem importância reconhecida no campo gerencial, estando presente em todas as investigações realizadas. O processo de reflexão crítica, no entanto, foi evidenciado em apenas um dos estudos (SILVA; REBELO; CUNHA, 2006), corroborando que uma perspectiva mais crítica na aprendizagem de gestores, tal como aponta Reynolds (1998), raramente atinge o meio gerencial ou a educação de gestores. A necessidade de desenvolvimento da consciência social e de mudança de consciência advinda da reflexão crítica, tal como Unger (1991) e Morin (2003) destacam como essenciais para o mundo contemporâneo, é apontada nos estudos desenvolvidos por Moraes (2000) e Bitencourt (2001), revelando a importância de integrar essa perspectiva à educação gerencial.

Os estudos aqui analisados salientam a importância da reflexão crítica no processo de aprendizagem dos gestores, bem como do autodesenvolvimento e da mudança de consciência. Estes aspectos também podem ser identificados na teoria da aprendizagem transformadora. Visto que a educação gerencial tem sido alvo de críticas, busca-se aqui ampliar a discussão acerca da aprendizagem gerencial à luz dessa teoria oriunda do campo da educação de adultos.

\section{Teorla da Aprendlzagem Transformadora: suas Contribulções para a Educação em Administração}

A teoria da aprendizagem transformadora está voltada para a educação de adultos e envolve a aprendizagem em contextos formais e informais. Ela dirige-se à interseção entre o individual e o social, dimensões coexistentes e igualmente importantes, já que os indivíduos são constituídos em sociedade (CRANTON, 2006). Mezirow (1981) é reconhecido como o formulador inicial desta teoria de aprendizagem, cujos fundamentos epistemológicos encontram-se no construtivismo. Ele sofreu influências das obras de autores críticos como Paulo Freire e Jurgen Habermas.

O contato e aproximação de Mezirow com o conceito de conscientização desenvolvido por Freire - que se refere ao processo pelo qual os adultos dão-se conta da realidade sociocultural que molda suas vidas, bem como sua capacidade de transformá-la através da ação - foi o dilema desorientador que desencadeou sua própria experiência de aprendizagem transformadora, levando-o a perceber que esta era uma dimensão crítica que faltava em seu trabalho (HENDERSON, 2002). Freire (1970), um dos pioneiros, no Brasil, a trabalhar com a noção da aprendizagem de adultos, propõe uma prática de ensino que valorize a cultura dos alunos e que desenvolva sua criticidade e inquietude, indicando a necessidade de buscar-se a verdadeira causalidade dos fenômenos sociais por meio da interpretação profunda dos problemas vividos, assimilando criticamente a realidade. 
Uma das tarefas mais importantes da prática educativo-crítica é propiciar as condições em que os educandos em suas relações uns com os outros e todos com o professor ensaiam a experiência profunda de assumir-se [...] como ser social e histórico, como ser pensante, comunicante, transformador, criador, realizador de sonhos, capaz de ter raiva porque capaz de amar (FREIRE, 1999, p. 46).

A aprendizagem é entendida por Mezirow (1998, p.190) como "o processo de utilizar uma interpretação prévia para construir uma interpretação nova ou revisada do significado da experiência de alguém para guiar futuras ações". A aprendizagem transformadora objetiva transformações nos quadros de referência dos indivíduos, de modo consciente, por intermédio da reflexão crítica sobre pressupostos construídos de modo acrítico. Segundo o autor, a transformação de perspectivas e o reconhecimento do papel essencial desempenhado pela reflexão crítica suprem lacunas importantes na teoria sobre aprendizagem de adultos e possibilitam a conscientização de por que se atribui determinado sentido à realidade.

O processo de aprendizagem é focado, moldado e delimitado por um quadro de referências (estruturas de significado) que envolvem perspectivas de significado, um amplo conjunto de predisposições resultantes de pressupostos psicoculturais que determinam os horizontes das expectativas dos indivíduos. As perspectivas de significado operam como um conjunto de códigos que moldam significativamente sensações e delimitam percepções, sentimentos e cognição. Os três tipos de códigos existentes são: 1) sociolingüísticos (ex.: normas sociais); 2) psicológicos (ex.: traços de personalidade);e 3) epistêmicos (ex.: estilos de aprendizagem) (MEZIROW, 1981).

A transformação de perspectivas de significados passa por um processo emancipatório de conscientização crítica, visando ao entendimento de como e por que a estrutura de pressupostos psicoculturais restringe a forma de um indivíduo ver a si próprio e a seus relacionamentos. A estrutura de pressupostos é reconstituída de modo a permitir uma integração mais inclusiva e discriminante da experiência, bem como um agir em consonância com essa nova compreensão (MEZIROW, 1981, p.6). Uma perspectiva superior envolve permeabilidade suficiente para permitir acesso a outras perspectivas, possibilitando movimentos para perspectivas ainda mais inclusivas e discriminantes. A transformação na perspectiva pessoal resultante é o que Freire denomina conscientização e Habermas, ação emancipatória (MEZIROW, 1981).

A segunda dimensão do quadro de referências pessoais é o esquema de significado, um agrupamento de conceitos, crenças, juízos e sentimentos que formatam determinada interpretação. Esquemas de significado são manifestações específicas das perspectivas de significado (MEZIROW, 1994). O autor ressalta que há resistência natural à aprendizagem de qualquer coisa que não se ajuste às estruturas de significado pessoais. Dadas a forte necessidade de compreensão dos significados das experiências pessoais e a limitação das estruturas de significado dos indivíduos, um grande esforço é empreendido em direção ao desenvolvimento de pontos de vista mais funcionais (mais inclusivos, discriminatórios e integrativos) das experiências pessoais (MEZIROW, 1994, p. 223).

As estruturas de significado são transformadas pela reflexão, envolvendo a crítica de pressupostos para determinar se crenças adquiridas anteriormente permanecem funcionais, examinando suas origens, natureza e consequências. O desencadeamento da reflexão ocorre a partir do confronto com um dilema desorientador. A gravidade desse dilema ou de um trauma influencia a probabilidade de transformação. Sob a intensa pressão de circunstâncias externas (morte de um parceiro, por exemplo), uma mudança de perspectiva é mais provável de acontecer. A mudança de perspectiva pode ocorrer de forma súbita ou como um movimento sucessivo de transformações que permitem a revisão de pressupostos específicos sobre si e sobre outros até que a estrutura de pressupostos transforma-se (MEZIROW, 1981).

Mezirow (1991) distingue três tipos de reflexão: (a) reflexão sobre conteúdo, a qual examina o conteúdo ou descrição de um problema; (b) reflexão sobre processo, que envolve uma revisão nas estratégias de solução de problemas utilizadas; (c) reflexão sobre premissas, que ocorre quando o problema em si é questionado. A maioria das reflexões ocorre dentro de um contexto de solução de problemas, envolvendo o conteúdo, o processo ou a premissa do problema. As mudanças de pensamento e transformações de esquemas de significado ocorrem a partir da reflexão sobre o conteúdo e os processos dos problemas cotidianos. Reflexões sobre conteúdo e processo pertencem às quatro formas de aprender existentes: 1) refinando ou elaborando 
esquemas de significado; 2) aprendendo novos esquemas de significado; 3) transformando esquemas de significado; 4) transformando perspectivas de significado (MEZIROW, 1994).

A reflexão sobre premissas possibilita que o sistema de crenças dos indivíduos (perspectivas de significado) possa ser examinado pela analise de suas origens, natureza e consequências, para determinar se crenças adquiridas anteriormente permanecem funcionais. As aprendizagens que envolvem a reflexão crítica sobre as premissas de um problema ou do próprio indivíduo podem transformar perspectivas de significado, uma experiência de aprendizagem mais significativa e menos frequente. Como mencionado anteriormente, a transformação decorrente pode resultar de um evento importante na vida de uma pessoa ou do acúmulo de transformações interligadas nos esquemas de significados (MEZIROW, 1994).

A reflexão crítica de pressupostos (MEZIROW, 1998) é, portanto, um conceito central para o entendimento da teoria transformadora da aprendizagem de adultos e de como adultos aprendem a pensar por si próprios, ao invés de agir somente a partir de conceitos, valores e sentimentos de outras pessoas. O que diferencia a reflexão crítica de outra reflexão qualquer é que ela implica uma avaliação do que está sendo refletido. A reflexão crítica pode ser implícita (escolhas irrefletidas baseadas em valores assimilados) ou explícita (tornando consciente o processo de escolha para examinar e avaliar as razões de uma escolha).

O processo de aprendizagem transformadora envolve algumas fases identificadas em estudos empíricos, embora nem sempre todas as etapas ocorram ou sigam necessariamente uma seqüência linear (MEZIROW, 1991). Henderson (2002, p. 203), em revisão realizada sobre os trabalhos desenvolvidos por Mezirow, Brookfield e Freire, identifica quatro fases no processo de aprendizagem transformadora, comuns aos três autores:

um evento disruptivo ocorre na vida do aprendiz que desafia sua visão do mundo;

o aprendiz então reflete criticamente sobre crenças, pressupostos e valores que moldam a perspectiva corrente;

o aprendiz desenvolve uma nova perspectiva para lidar com as discrepâncias trazidas à tona pelo evento desencadeador;

o aprendiz integra a nova perspectiva em sua vida.

Mezirow $(1981,1994)$ desenvolve a teoria transformadora da aprendizagem de adultos a partir da diferenciação dos tipos de conhecimento realizada por Habermas, considerando seu trabalho seminal para o entendimento da aprendizagem e da educação. Estes domínios de aprendizagem distintos, mas inter-relacionados, derivam de três interesses cognitivos primários - o técnico, o prático e o emancipatório - originados de diferentes aspectos da existência social: trabalho, interação e poder. Cada um destes domínios de aprendizagem sugere diferentes formas e necessidades de aprendizagem apresentados no Quadro 2. 


\begin{tabular}{|c|l|}
\hline Domínio & \multicolumn{1}{c|}{ Definição } \\
\hline Técnico & $\begin{array}{l}\text { Problemáticas solucionáveis através da realização de testes empíricos, de mensuração objetiva, são } \\
\text { consideradas do domínio do conhecimento técnico, relacionadas à aprendizagem instrumental. Ela } \\
\text { permite o controle ou a manipulação do meio ambiente, a predição de eventos físicos/sociais } \\
\text { observáveis e tomadas de decisão apropriadas. }\end{array}$ \\
\hline Prático & $\begin{array}{l}\text { Baseia-se na necessidade de os seres humanos entenderem-se pela linguagem, envolvendo interação } \\
\text { ou ação comunicativa, denominado conhecimento prático ou comunicativo. A aprendizagem } \\
\text { comunicativa "envolve valores, intenções, sentimentos, decisões morais, ideais e conceitos } \\
\text { normativos os quais podem ser definidos apenas pelos seus contextos" (MEZIROW, 1994, p. 225). } \\
\text { Nesse caso, busca-se não um critério de definição de verdade, mas de validade ou justificação de } \\
\text { acordo com as crenças pessoais, através de figuras de autoridade, pela força, ou através de discurso } \\
\text { racional. Para compreender plenamente o significado do que está sendo comunicado, é preciso } \\
\text { tornar-se reflexivo criticamente, é necessário entender o contexto da pessoa para apreender o } \\
\text { significado do que ela está comunicando. }\end{array}$ \\
\hline $\begin{array}{l}\text { Eeriva de um questionamento dos conhecimentos instrumentais e comunicativos. Envolve o } \\
\text { interesse em autoconhecimento, incluindo o interesse no modo como a história pessoal de alguém se } \\
\text { expressa na maneira como essa pessoa vê a si mesma, ao seu papel e às suas expectativas sociais. A } \\
\text { emancipação seria de forças libidinais, institucionais ou ambientais assumidas como incontroláveis, } \\
\text { as quais limitam opções e controle racional sobre a vida das pessoas. O processo de auto- } \\
\text { questionamento e de questionamento do sistema social no qual se vive leva à aquisição de } \\
\text { aprendizagem emancipatória que, por sua vez, é transformadora. }\end{array}$ \\
\hline
\end{tabular}

Quadro 2 - Domínio de Aprendizagem.

Fonte: Mezirow (1981, 1994, 1998)

A aprendizagem emancipatória pode ocorrer em ambientes educacionais formais ou informais, tais como grupos de desenvolvimento comunitário, programas de desenvolvimento profissional, movimentos políticos e ambientais. A aprendizagem transformadora pode, portanto, se efetivar em qualquer ambiente onde ocorra aprendizagem. Ao adquirir conhecimento técnico, por exemplo, uma pessoa pode aumentar sua autoconfiança e mudar sua percepção sobre seu lugar no mundo, obtendo assim uma aprendizagem emancipatória. Em algumas ocasiões, as pessoas adquirem uma série de conhecimentos instrumentais e comunicativos até que esses conhecimentos se integrem. Em outros casos, a aprendizagem emancipatória não ocorre, por estarem envolvidas apenas a aquisição de novos conhecimentos ou a elaboração de conhecimentos anteriores, processos de aprendizagem que não abarcam questionamento de crenças ou pressupostos pré-existentes (CRANTON, 2006).

Aprendizagens significativas integram conhecimentos instrumentais e comunicativos. A aprendizagem emancipatória efetiva-se quando esses conhecimentos mudam a perspectiva de uma pessoa sobre si mesma e sobre o mundo. Ou seja, somente quando aprendizagens instrumentais e comunicativas conduzem ao questionamento de visões anteriores sobre o mundo e sobre si próprio é que existe o potencial para a ocorrência da aprendizagem transformadora. A aprendizagem transformadora não ocorre independentemente de outros tipos de aprendizagem (CRANTON, 2006).

A ação refletida frequentemente envolve a superação de barreiras emocionais, de conhecimentos e situacionais. Ela implica tomada de decisão, mas não necessariamente mudança de comportamento imediata. Habermas, tal como Hegel e Marx, rejeita a ideia de que uma consciência transformada em determinada situação possa automaticamente conduzir a uma forma de ação previsível (MEZIROW, 1981, 1994).

Aprendizagens transformadoras que envolvem perspectivas sociolinguísticas resultam em aprendizes motivados para tomar ações sociais coletivas com o objetivo de modificar práticas sociais, instituições ou sistemas. Uma ação social pode consistir em trabalhar em sintonia com indivíduos que pensam de maneira similar, ou ainda coletivamente, para efetuar mudanças tanto culturais como políticas em relacionamentos interpessoais, nas famílias, organizações, comunidades ou nações. A ação transformadora pode produzir mudanças nos indivíduos e na forma como eles aprendem. Ao invés de aceitar passivamente realidades definidas por outros, a educação para desenvolver competências comunicativas requer o cultivo da habilidade do aprendiz para negociar significados e objetivos (MEZIROW, 1994).

O papel dos educadores na aprendizagem transformadora envolve o auxílio aos aprendizes em seus processos de transformação de experiências e a facilitação de ações refletidas, que os ajudem a superarem barreiras 
situacionais, de conhecimento ou emocionais e que favoreçam o desencadeamento de aprendizagens transformadoras. O desenvolvimento de um adulto é representado pela realização progressiva de sua capacidade para participar em um discurso de forma racional, plena e livremente, a fim de adquirir um entendimento mais amplo, discriminante, permeável e integrativo de suas experiências, de modo a guiar suas ações (MEZIROW, 1994, p. 226).

Discurso, para Mezirow (1994), refere-se a um tipo especial de diálogo focado em conteúdo, na tentativa de justificar crenças pela argumentação de razões e pelo exame dos prós e contras de pontos de vista concorrentes. Razões, argumentos e evidências são avaliados para realizar um julgamento que é considerado válido até que novas evidências, argumentos ou pontos de vista sejam encontrados, continuando o processo de discurso. $\mathrm{O}$ consenso encontra-se, portanto, sempre sujeito a revisões.

A participação em um discurso, processo central nas comunicações e aprendizagem humanas, demanda uma série de condições, consideradas ideais: (a) ter informação completa e acurada; (b) estar livre de coerção; (c) estar apto a pesar evidências e avaliar argumentos 'objetivamente'; (d) estar aberto a pontos de vista alternativos e a considerar o modo dos outros sentirem e pensarem; (e) estar apto a se tornar criticamente reflexivo sobre suposições e suas consequências; (f) ter oportunidades iguais para participar em vários papéis de discurso; (g) desejar aceitar o consenso informado, objetivo e racional como um teste legítimo de validade até que novas perspectivas, evidências ou argumentos surjam (MEZIROW, 1994, p. 225).

Essas condições são também ideais para o processo de aprendizagem, implicando liberdade, igualdade, tolerância, educação e participação democrática como condições essenciais da comunicação e da aprendizagem humanas (MEZIROW, 1994). Para compreender plenamente o significado do que está sendo comunicado, englobando sentimentos, valores, ideais, decisões morais e intenções, é preciso se tornar reflexivo criticamente, é necessário entender o contexto da pessoa para apreender o significado do que ela está comunicando. (MEZIROW, 1998).

Apresentados os pontos considerados essenciais à teoria da aprendizagem transformadora, pode-se dizer que esta abordagem, a priori, contempla a possibilidade de uma formação gerencial que busque o desenvolvimento de uma postura crítica e reflexiva, levando em consideração a subjetividade dos indivíduos. Ela abriria, desta forma, a possibilidade de uma educação que vise à inserção crítica do gestor na sociedade, incorporando as dimensões ética, sócio-econômica, política, cultural e histórica no processo de ensino e de aprendizagem.

\subsection{Implicações da Teoria de Aprendizagem Transformadora no Campo Organizacional: literatura e estudos empíricos}

Embora no Brasil poucos estudos tenham sido desenvolvidos à luz das teorias de aprendizagem de adultos e, mais especificamente, da teoria da aprendizagem transformadora no campo organizacional, é possível identificar algumas contribuições oportunizadas pela aproximação/integração destes campos de conhecimento, bem como barreiras e limitações.

Taylor (2007), a partir da revisão crítica sobre as pesquisas empíricas a respeito da teoria de aprendizagem transformadora, realizadas no período de 1999 a 2005, identificou a proliferação de estudos sobre o tema em periódicos internacionais. Muitos destes estudos concentram-se na tentativa de forjar a aprendizagem transformadora em diferentes áreas de conhecimento. $\mathrm{O}$ autor concluiu que, apesar do crescente interesse acerca da teoria da aprendizagem transformadora, ainda há muito a aprender a respeito de como as pessoas revisam suas interpretações sobre o mundo que as cerca, capacidade necessária para atuar em contextos em constante transformação como o das organizações contemporâneas. Entre as críticas elaboradas por Taylor (2007) aos estudos que analisou, destacam-se: (a) a forte ênfase atribuída aos aspectos positivos da aprendizagem transformadora; (b) um aspecto raramente discutido nos estudos sobre a aprendizagem transformadora é: qual o seu objetivo?; (c) a ausência da exploração das consequências negativas das transformações de perspectivas, tanto pessoais como sociais. Em estudo desenvolvido por Kilgore e Bloom (2002), os pesquisadores identificaram, junto a mulheres em crise, que, mesmo expressando com sucesso o discurso aprendido em um programa educacional, elas não experienciaram realmente uma transformação. Para sobreviver em vários contextos de suas vidas, elas aprenderam o script das pessoas no poder, mantendo muitas perspectivas contraditórias. Segundo Kilgore e Bloom (2002, p. 131), a teoria de aprendizagem transformadora de Mezirow falha em não 
(...) reconhecer o self não unitário e vozes de mulheres (...) Porque mulheres em crise estão em constante estado de fragmentação, elas não podem ser sujeitos de uma pedagogia transformadora que assume um self unificado.

Taylor (2007) também identificou o caráter essencial da reflexão crítica para a aprendizagem transformadora. Apesar disso, destacou a falta de discriminação na identificação da reflexão crítica (reflexão sobre premissas) entre participantes dos estudos, pois normalmente assumem postura de que todas as formas de reflexão são significativas. Complementando esta ideia $\operatorname{Kreber}(2004$, p. 43-44) ressalta que:

Reflexão sobre o ensino começa com a identificação de pressupostos e crenças adquiridos, mas não deve parar por aí. É preciso ir além e envolver o engajamento em processos de aprendizagem particulares (instrumental, comunicativo e emancipatório) que vão tanto conduzir a uma nova validação ou a uma rejeição de nossos pressupostos.

As pesquisas envolvendo o desenvolvimento de aprendizagens transformadoras, segundo Taylor (2007), normalmente estão confinadas a ambientes formais de aprendizagem. $\mathrm{O}$ autor aponta a necessidade de se explorarem outros contextos, especialmente os mais informais, menos controlados por um instrutor e mais suscetíveis a influências externas. Raros estudos acerca da aprendizagem transformadora examinam o papel da cultura e das mudanças sócio-culturais na sociedade, sendo pouco compreendida esta relação. Um dos principais achados de pesquisa foi o reconhecimento de que mudanças epistemológicas entre participantes não são suficientes para que a transformação ocorra, ou seja, a conscientização cognitiva de pressupostos epistêmicos subjacente e a mudança na forma de fazer sentido não são suficientes para garantir que ocorra a aprendizagem transformadora.

Cunliffe (2004) ressalta a importância do conceito de reflexão crítica para a educação gerencial porque ,pensando de modo mais crítico a respeito dos próprios pressupostos e ações, é possível desenvolver maneiras mais colaborativas, responsáveis e éticas para gerir as organizações. A autora acredita que a responsabilidade da educação gerencial engloba não apenas tornar os gestores cidadãos mais eficazes nas organizações, mas também auxiliá-los a tornarem-se pensadores críticos e profissionais morais.

A necessidade de incorporação de uma perspectiva crítica na educação e no desenvolvimento gerencial, dado seu poder societal e global, é destacada por Reynolds (1998). Ele defende que a educação gerencial, quer nas organizações, quer em instituições educacionais, pode auxiliar o exame dos efeitos da história e do contexto na vida profissional de gestores, desenvolvendo quadros de referência para entender esses processos.

Brooks (1999) assinala a utilidade do papel da reflexão crítica para organizações em meio a mudanças radicais, as quais requerem o questionamento de seus valores, pressupostos fundamentais e crenças para realizarem mudanças profundas. O questionamento possibilita aperfeiçoar práticas de trabalho; lidar com dilemas éticos e morais; avaliar metas e estratégias organizacionais. Henderson (2002) comenta que a teoria da aprendizagem transformadora (que enfoca a mudança individual) e a teoria da mudança transformacional (que enfoca a mudança organizacional) são complementares e salienta o papel essencial da reflexão crítica tanto para a mudança individual como organizacional.

De acordo com Van Woerkom (2004), os comportamentos no trabalho resultantes de reflexão crítica, tais como reflexões acerca de si mesmo em relação ao trabalho; compartilhamento de opiniões críticas; solicitações de feedback; desafios a pensamentos grupais, estimulam a aprendizagem individual e permitem a otimização de processos de trabalho ou a análise crítica e a tentativa de mudança de valores organizacionais, dando início, no plano organizacional, a processos de aprendizagem de double-loop. Como facilitadores do processo de reflexão crítica, Brooks (1999) assinala a exposição a diferentes perspectivas; a realização de tarefas abertas; o encorajamento de questionamentos; o feedback e participação, dentre outros aspectos.

Com relação às barreiras para que a reflexão crítica ocorra, Brooks (1999) destaca a competição interna; a evitação de conflitos; as ações tomadas sem consideração adequada de seus benefícios e consequências. Van Woerkom (2004) salienta que o processo de reflexão crítica pode ser possibilitado pelo auxílio de outros, através de feedbacks, que descortinam novos pontos de vista e uma capacidade de lidar com a pressão social. Os indivíduos que ousam criticar teorias esposadas podem ser vistos como causadores de problemas e serem isolados no ambiente organizacional. 
No campo de desenvolvimento de recursos humanos, duas visões principais concorrem: a que defende a supremacia da importância da performance, objetivando aumentá-la, e a que defende a importância da aprendizagem, que visa desenvolver indivíduos que, em última análise, contribuem para o desenvolvimento da prosperidade organizacional (YANG, 2004). Embora a reflexão crítica seja, muitas vezes, considerada irrelevante na perspectiva que enfoca a performance, para Van Woerkom (2004), ela não se opõe à orientação para resultados, uma vez que a visão de longo prazo a respeito de performance engloba a aprendizagem adaptativa e a aprendizagem resultante de reflexão crítica. A autora diz que a definição de performance organizacional em uma projeção de longo prazo não pode limitar-se à perspectiva meramente econômica, já que empreendimentos socialmente responsáveis e boa reputação são quesitos importantes para a continuidade de muitas organizações. Yang (2004) salienta que a visão da área de desenvolvimento de recursos humanos como capitalista, desumana e cultuadora de prosperidade, difundida entre a área de educação de adultos, é uma das dificuldades para a aproximação destas áreas de conhecimento.

Apesar de a tentativa de aproximação de princípios e práticas da educação voltada para a aprendizagem de adultos à educação gerencial ainda constituir-se em desafio, principalmente no que diz respeito aos posicionamentos ontológicos e epistemológicos, Brookfield visualiza a possibilidade de se estabelecerem algumas articulações, desde que a concepção central adotada na educação contemple a promoção de valores e práticas democráticos (BROOKFIELD; KALLIATH; LAIKEN, 2006). A exploração das possibilidades de contribuição da aprendizagem transformadora para a aprendizagem gerencial ainda é recente, pode-se, contudo, considerá-la uma alternativa, evidentemente com limitações, como identificado por Taylor (2007), por exemplo, para lançar luz à discussão acerca de alguns dos desafios propostos à aprendizagem gerencial.

\section{Para Refletir: Criticamente ou Não?}

Longe de aqui se defender a supremacia de uma ou outra abordagem (da reflexão sobre a da reflexão crítica ou vice-versa), é importante sublinhar que existem diferenças significativas entre elas. Está claro que reflexão crítica é qualitativamente diferente do conceito de reflexão. A reflexão focaliza o imediato, apresenta e discute detalhes de uma tarefa ou problema, estabelece uma análise de natureza mais prática e técnica. A reflexão crítica envolve análise do poder, controle e exame da construção dentro da qual a tarefa ou problema estão situados. A teoria da aprendizagem experiencial que sustenta a noção de reflexão leva em conta aspectos causais na resolução de um problema. A análise do contexto está frequentemente autoreferenciada, mas raramente envolve a análise dos processos sociais e políticos, atuais ou históricos.

A reflexão crítica, oriunda da pedagogia crítica e uma das ideias centrais da teoria da aprendizagem transformadora, ressalta a importância de se considerarem a natureza socialmente situada da experiência para a reflexão ter algum significado e a emancipação coletiva do indivíduo e reconhece a natureza essencialmente social, política e histórica da experiência. (REYNOLDS, 1998; CUINLIFFE, 2002). Pergunta-se então, seria possível estabelecer reflexão crítica em organizações ditas modernas? Conforme Freire, a prática organizativa e o processo de ensino-aprendizagem são inseparáveis. A prática pedagógica nesta abordagem, por uma questão de coerência interna, ocorre como um exercício de auto-organização entre aqueles que a utilizam e somente é consolidada durante o próprio processo de auto-organização dos sujeitos. Isto não seria mais profícuo em organizações não-governamentais, movimentos sociais, cooperativas ?

Para Reynolds (1998), a abordagem da reflexão crítica não desconsidera a relevância da educação em administração para a sociedade, uma vez que as organizações têm papel atuante e administrar não é uma atividade neutra nem desinteressada. A abordagem da reflexão crítica propõe que se discutam o envolvimento e os efeitos da administração na vida dos indivíduos e da sociedade e seu futuro. Wilson observa que:

(...) o que nós não compreendemos é que refletir sobre pensamento e ação (teoria e prática) não é um tema individual... porque nossa teoria e prática estão situadas dentro e emanam de tradições históricas; não praticamos como indivíduos, mas como integrantes de comunidades que refletem valores, convicções e normas sobre os meios e fins da prática e constituem nosso trabalho educacional diariamente (1994, p 188).

Nesta linha, considerando-se que a educação em administração também formula e dissemina conhecimento, tor n a-se oportuno trazer algumas reflexões lançadas por Bauman (2007). Este sociólogo estabelece uma crítica 
sobre a visão de aprendizagem ao longo da vida - proposta e divulgada pela Comunidade Européia - e discute a noção do que ele denomina "capacitamento", em capítulo intitulado "Aprendendo sobre a Areia Movediça'. $\mathrm{Na}$ visão da Comunidade Européia, a aprendizagem e a educação precisam ter utilidade e devem ocorrer de forma permanente e efetiva, ao longo da vida, com o objetivo de desenvolver nos indivíduos capacidades para que eles se adaptem rapidamente às aceleradas mudanças mundiais, persigam individualmente seus objetivos e obtenham sucesso.

Para o Bauman, estar 'capacitado' significa "ser capaz de fazer escolhas e atuar efetivamente sobre as escolhas feitas, e isso, por sua vez, significa a capacidade de influenciar o espectro de escolhas disponíveis e os ambientes sociais em que as escolhas são feitas e perseguidas" (2007, p. 162). Isto exige dos indivíduos capacidades para que obtenham um bom desempenho e "poderes" para influenciar os objetivos e normas do "jogo planejado por outros", ou seja, além de habilidades pessoais, exige também "poderes sociais". Baumann comenta que estar capacitado implica realizar a construção e a reconstrução de vínculos pessoais, "de manter um diálogo, de negociar, de obter a compreensão mútua e de administrar ou resolver os inevitáveis conflitos em qualquer instância da vida compartilhada" (op. cit., p. 163). Diferente do que propõe a Comunidade Européia, o objetivo da educação deveria ser a reconstrução do espaço público. Retorna, pois, o questionamento anterior: seria possível transpor isto para o campo das organizações? Sem a intenção de responder, cabe lembrar Freire:

Isso não significa negar os condicionamentos genéticos, culturais, sociais a que estamos submetidos. Significa reconhecer que somos seres condicionados mas não determinados. Reconhecer que a História é tempo de possibilidades e não de determinismos, que o futuro [...] é problemático e não inexorável (1999, p.19).

Taylor (2007), em seu estudo, lança algumas questões acerca da aprendizagem transformadora, aqui reproduzidas e que permanecem em aberto, tal como a responsabilidade dos alunos no desenvolvimento de aprendizagens transformadoras. Alguns estudantes engajam-se abertamente neste processo, outros se recusam a participar. O que fazer para diminuir resistências? É necessário que todos participem ou esta é uma questão de livre arbítrio? Existe ainda falta de entendimento acerca do impacto de forjar a aprendizagem transformadora em sala de aula sobre outros estudantes, sobre o educador, sobre a instituição e sobre outras pessoas importantes na vida dos aprendizes.

Embora o presente trabalho não responda todas as questões e lacunas identificadas nos estudos relacionados à aprendizagem transformadora, espera-se que tenha instigado a reflexão e apontado algumas preocupações acerca da educação gerencial que visa à inserção crítica do gestor na sociedade e à incorporação das dimensões ética, sócio-econômica, política, cultural e histórica no processo de ensino e de aprendizagem. Aprender a pensar por si próprio, liberando-se de pressupostos condicionados sobre o mundo, sobre os outros e sobre si mesmos, revela-se crucial para o mundo do trabalho, para a cidadania e para a tomada de decisões morais de gestores em uma sociedade em rápida mudança. Trata-se, contudo, de uma construção complexa e paradoxal. Em um contexto em que a educação ao longo da vida é necessária para que se tenham escolhas e, mais ainda, para que se mantenham condições que as tornem possíveis e tangíveis (BAUMAN, 2007), parece fundamental o papel da reflexão crítica sobre pressupostos, aspecto central da teoria da aprendizagem transformadora. (Re)aberta esta discussão, sugere-se a realização de estudos que busquem compreender, junto ao campo organizacional, este e outros conceitos oriundos do campo da educação de adultos, uma vez que os desafios atuais requerem a formulação de novos questionamentos e, possivelmente, a identificação de novas alternativas e perspectivas, a partir da aproximação de diferentes campos teóricos, quando isto for possível.

${ }^{3}$ In: Vida líquida. Rio de Janeiro: Jorge Zahar, 2007. 


\section{Referênclas}

ALVES, R. Filosofia da ciência: introdução ao jogo e a suas regras. São Paulo: Edições Loyola, 2005.

ANTONELLO, C. Alternativas de Articulação Entre Programas de Formação Gerencial e as Práticas de Trabalho: uma contribuição no Desenvolvimento de Competências. 2004. 378f. Tese (Doutorado em Administração) - Programa de Pós-Graduação em Administração, Escola de Administração, Universidade Federal do Rio Grande do Sul, Porto Alegre, 2004.

AXLEY, S. R.; MCMAHON, T.R. Complexity: a frontier for management education. Journal of Management Education, v. $30, n .2, p$. 295-315, Apr. 2006.

BAUMAN, Z. Vida líquida. Rio de Janeiro: Jorge Zahar, 2007.

BITENCOURT, C. A gestão de competências gerenciais: a contribuição da aprendizagem organizacional. 2001. 173f. Tese (Doutorado em Administração) - Programa de Pós-Graduação em Administração, Escola de Administração, Universidade Federal do Rio Grande do Sul, Porto Alegre, 2001.

BROOKFIELD, S.; KALLIATH, T.; LAIKEN, M. Exploring the connections between adult and management education. Journal of Management Education, v. 30, n.6, dec. 2006

BROOKS, A. Critical reflection as a response to organizational disruption. Advances in Human Resources, v. 3, p. 66-79, 1999.

CLOSS, L. ARAMBURÚ, J. ANTUNES, E. Produção Científica sobre o Ensino em Administração: uma Avaliação Envolvendo o Enfoque do Paradigma da Complexidade. XXX Encontro Nacional da ANPAD: Salvador, BA, 2006.

CRANTON, P. Understanding and Promoting Transformative Learning: A Guide for Educators of Adults, 2nd Edition. San Francisco: Jossey-Bass, 2006.

CUNHA, M. Prática gerencial: experiências vividas de mudança. 2003. 183f. Tese (Doutorado em Engenharia da Produção) Tese Centro Tecnológico, Universidade Federal de Santa Catarina, Florianópolis, 2003.

CUNLIFFE, A. On becoming a critically reflexive practicioner. Journal of Management Education, v. 28, n. 4, Aug. 2004.

CUNLIFFE, A. Reflexive dialogical practice in management learning. Management Learning, v. 33, n. 1; p. 35-52, 2002.

FREIRE, Paulo. Pedagogia do oprimido. Rio de Janeiro: Paz e Terra, 1970.

FREIRE, Paulo. Pedagogia da autonomia: saberes necessários à prática educativa. São Paulo: Paz e Terra, 1999.

GADOTTI, M. Perspectivas atuais da educação. São Paulo em Perspectiva, v. 14, n.2. São Paulo, abr./jun. 2000.

GOTTWALD, G. Aprendizagem de executivos no setor automobilístico: estudo de caso na Volkswagen/Audi do Brasil. $2001.150 f$. Dissertação (Mestrado em Engenharia da Produção) Centro Tecnológico, Universidade Federal de Santa Catarina, Florianópolis, 2001.

GROHMANN, M. Influências de um curso de pós-graduação no processo de aprendizagem gerencial. 2004. 305f. Tese (Doutorado em Engenharia da Produção) - Centro Tecnológico, Universidade Federal de Santa Catarina, Florianópolis, 2004.

GUATTARI, F. As três ecologias. $14^{\mathrm{a}}$ ed. Campinas, SP: Papirus, 2003.

KOLB, D. A gestão e o processo de aprendizagem. In: STARKEY, Ken. Como as Organizações Aprendem. São Paulo: Ed. Futura/Zumble, 1997.

KILGORE, D.; BLOOM, L. R. When I'm down, it takes me a while': Rethinking Transformational Education through Narratives of Women in Crisis. Adult Basic Education, v. 12, p. 123-133, 2002.

KREBER, C. An Analysis of Two Models of Reflection and their Implications for Educational Development. International Journal for Academic Development, v. 9, p. 29-49, 2004.

HENDERSON, G. Transformative learning as a condition for transformational change in organizations. Human Resource Development Review, v. 1, n.2, p. 186-214, June 2002

LEITE, I.; GODOY, A.; ANTONELLO, C. O aprendizado da função gerencial: os gerentes como atores e autores do seu processo de desenvolvimento. Aletheia, n.23, p.7-41, jun. 2006

LUCENA, E. A natureza da aprendizagem de gerentes-proprietários do setor de varejo de vestuário de Florianópolis. 2001. Tese (Doutorado em Engenharia da Produção) - Centro Tecnológico, Universidade Federal de Santa Catarina, Florianópolis, 2001.

MEZIROW, J. A critical theory of adult learning and education. Adult Education Quarterly, 32, n. 1, p. 3-24, 1981

Understanding transformation theory. Adult Education Quarterly, v. 44, n. 4, p. 222-232, 1994

On critical reflection. Adult Education Quarterly, v.48, n.3, p.185-198, 1998

MORAES, L. A dinâmica da aprendizagem gerencial - o caso do Hospital Moinhos de Ventos. 2000. 233f. Dissertação (Mestrado em Engenharia da Produção) Centro Tecnológico, Universidade Federal de Santa Catarina, Florianópolis, 2000.

MORAES, L.: SILVA, M.; CUNHA, C. Aprendizagem gerencial: teoria e prática. RAE-eletrônica, v.3, n.1, jan./jun. 2004. 
MORIN, E. Ciência com consciência. Rio de Janeiro: Bertrand, 2003.

O método 1: a natureza da natureza. ${ }^{\mathrm{a}}$. ed. Porto Alegre: Sulina, 2003 a.

NICOLINI, A. Qual será o futuro das fábricas de administradores? Revista de Administração de Empresas, v. 43, n.2, p. 44-54, abr./jun. 2003.

PAES DE PAULA, A.P.; RODRIGUES, M.A. Pedagogia crítica no ensino da administração: desafios e possibilidades. In: Encontro Anual da Anpad XXX, 2006. Anais... Salvador: Associação Nacional dos Cursos de Pós-Graduação em Administração, 2006.

POSSAMAI, F. A influência da cultura da organização na aprendizagem de executivos: o caso da Tigre. 2005. 133f. Tese (Doutorado em Engenharia da Produção) - Centro Tecnológico, Universidade Federal de Santa Catarina, Florianópolis, 2005.

REYNOLDS, M. Reflection and critical reflection in management learning. Management Learning, v. 29, n.2, p. 183-200, 1998.

REYNOLDS, M. Critical reflection and management education: rehabilitating less hierarchical approaches. Journal of Management Education, v. 23, n. 5, 1999.

ROGLIO, K. O executivo reflexivo: arquiteto e facilitador de novas configurações organizacionais. 2006. 273f. Tese (Doutorado em Engenharia da Produção) - Centro Tecnológico, Universidade Federal de Santa Catarina, Florianópolis, 2006.

SCHÖN, D. The reflective practicioner. How Professionals Think in Action. New York: Basic Books Inc. Publishers, 1983.

SCHÖN, D. Educando o profissional reflexivo: um novo design para o ensino e a aprendizagem. Porto Alegre: Artmed, 2000.

SILVA, A.; REBELO, L.; CUNHA, C. Aprendizagem de gerentes: a perspectiva da experiência vivida. In: ENCONTRO ANUAL DA ANPAD, XXX, 2006. Anais... Salvador: Associação Nacional dos Cursos de Pós-Graduação em Administração, 2006.

TAYLOR, E. An update of transformative learning theory: a critical review os the empirical research (1999-2005). International Journal of Lifelong Education, v. 26, n.2, p.173-191, 2007

TONELLI, M.J. À beira de um ataque de nervos: um dia na vida de executivos em São Paulo. FGV-EASP/GV Pesquisa Relatório de Pesquisa No. 19/2005.

UNGER, N.M. O encantamento do humano: ecologia e espiritualidade. São Paulo: Loyola, 1991.

VAN WOERKOM, M. The concept of critical reflection and its implications for human resource development. Advances in Developing Human Resources, v. 6, n. 2, p. 178-192, 2004.

WILSON, Arthur L. To a middle ground: praxis and ideology in adult education. International Journal of Lifelong Education, v. 13, 3 p. 187-102, 1994

WOOD JR, T.; PAES DE PAULA, A.P. O fenômeno dos MPAs brasileiros: hibridismo, diversidade e tensões. Revista de Administração de Empresas, V. 44, n. 1, jan./mar. 29004.

YANG, B. Can adult learning theory provide a foundation for human resource development? Advances in Developing Human Resources, v. 6, n. 2, p. 129-145, 2004. 